\title{
Erratum to: The German Lipoprotein Apheresis Registry (GLAR) - almost 5 years on
}

\author{
V. J. J. Schettler ${ }^{1}$ C. L. Neumann ${ }^{2}$ C. Peter ${ }^{3,4}$ - T. Zimmermann ${ }^{3}$ - U. Julius ${ }^{5}$ E. Roeseler ${ }^{6}$ - F. Heigl ${ }^{7}$ • \\ P. Grützmacher ${ }^{8} \cdot$ H. Blume ${ }^{9} \cdot$ A. $\operatorname{Vogt}^{10} \cdot$ Scientific Board of GLAR for the German Apheresis Working \\ Group
}

(C) Springer-Verlag GmbH Germany 2017

\section{Erratum to:}

\section{Clin Res Cardiol Suppl}

\subsection{7/s11789-017-0089-9}

The column heads "Males" and "Females" were interchanged in Table 1 . The corrected version of Table 1 is reproduced here.

The sentence citing the table in the second paragraph of the Results section should read as follows: "Until 2015, the majority of patients were male ( 838 males vs 441 females) with most of them being 60 years or older (Table 1)."

The authors regret their error and apologise for any inconvenience caused.
Table 1 Age and sex distribution in the GLAR database (data interrogation until 2015)

\begin{tabular}{llll}
\hline Age & Females & Males & Total \\
\hline Under 18 & 0 & 0 & 0 \\
$18-30$ & 3 & 4 & 7 \\
$30-39$ & 6 & 21 & 27 \\
$40-49$ & 23 & 88 & 111 \\
$50-59$ & 105 & 231 & 336 \\
$60-69$ & 127 & 256 & 383 \\
70 and older & 177 & 238 & 415 \\
Total & 441 & 838 & 1279 \\
Oldest patient & & & 90 years old \\
Youngest patient & & & 20 years old \\
\hline
\end{tabular}

The online version of the original article can be found under doi: 10.1007/s11789-017-0089-9.

\footnotetext{
$\triangle$ V. J. J. Schettler

v.schettler@nz-goe.de

1 Center of Nephrology Göttingen GbR, An der Lutter 24, 37075 Göttingen, Germany

2 BRAVE e Benefit for Research on Arterial Hypertension, Dyslipidemia and Vascular Risk and Education e.V., Göttingen, Germany

3 BioArtProducts GmbH (B.A.P.), Rostock, Germany

4 Rostock Group (EXIM), Fraunhofer Institute for Cell Therapy and Immunology IZI, Rostock, Germany
}

5 Department of Medicine III, University Hospital Carl Gustav Carus, Technische Universität Dresden, Dresden, Germany

6 Center for Nephrology, Hypertension, and Metabolic Diseases, Hannover, Germany

7 Medical Care Centre Kempten-Allgäu, Kempten, Germany

8 Department of Medicine II for Nephrology, Hypertension and Vascular Risks, AGAPLESION Markus Hospital, Frankfurt, Germany

9 Scientific Institute for Nephrology (WiNe), Düsseldorf, Germany

10 Medizinische Klinik und Poliklinik 4, Universität München, Munich, Germany 